OPEN ACCESS

Edited by: Katarína Smolková, Institute of Physiology

(ASCR), Czechia

Reviewed by:

Tuuli Käämbre,

National Institute of Chemical Physics and Biophysics, Estonia David Vetvicka,

Charles University, Czechia Jakub Rohlena,

Academy of Sciences of the Czech Republic (ASCR), Czechia

*Correspondence:

Muh-Hwa Yang mhyang2@vghtpe.gov.tw

Specialty section:

This article was submitted to Cancer Metabolism,

a section of the journal Frontiers in Oncology

Received: 15 February 2020 Accepted: 22 April 2020 Published: 20 May 2020

Citation:

Sun N-Y and Yang M-H (2020) Metabolic Reprogramming and Epithelial-Mesenchymal Plasticity:

Opportunities and Challenges for Cancer Therapy. Front. Oncol. 10:792. doi: 10.3389/fonc.2020.00792

\section{Metabolic Reprogramming and Epithelial-Mesenchymal Plasticity: Opportunities and Challenges for Cancer Therapy}

\author{
Nai-Yun Sun ${ }^{1,2}$ and Muh-Hwa Yang ${ }^{1,2,3 *}$ \\ ${ }^{1}$ Institute of Clinical Medicine, National Yang-Ming University, Taipei, Taiwan, ${ }^{2}$ Cancer Progression Research Center, National \\ Yang-Ming University, Taipei, Taiwan, ${ }^{3}$ Division of Medical Oncology, Department of Oncology, Taipei Veterans General \\ Hospital, Taipei, Taiwan
}

Metabolic reprogramming and epithelial-mesenchymal plasticity are both hallmarks of the adaptation of cancer cells for tumor growth and progression. For metabolic changes, cancer cells alter metabolism by utilizing glucose, lipids, and amino acids to meet the requirement of rapid proliferation and to endure stressful environments. Dynamic changes between the epithelial and mesenchymal phenotypes through epithelial-mesenchymal transition (EMT) and mesenchymal-epithelial transition (MET) are critical steps for cancer invasion and metastatic colonization. Compared to the extensively studied metabolic reprogramming in tumorigenesis, the metabolic changes in metastasis are relatively unclear. Here, we review metabolic reprogramming, epithelial-mesenchymal plasticity, and their mutual influences on tumor cells. We also review the developing treatments for targeting cancer metabolism and the impact of metabolic targeting on EMT. In summary, understanding the metabolic adaption and phenotypic plasticity will be mandatory for developing new strategies to target metastatic and refractory cancers that are intractable to current treatments.

Keywords: cancer metabolism, aerobic glycolysis, epithelial-mesenchymal plasticity, metastasis, drug resistance

\section{BACKGROUND: ADAPTIONS OF CANCER CELLS FOR TUMOR GROWTH AND METASTASIS}

Cancer cells are characterized by rapid proliferation and metastasis (1). Adaptation of cancer cells to stressful environments is mandatory to ensure their growth and metastasis. Cancer cells utilize metabolic reprogramming to meet their energy requirements for growth (2), whereas the dynamic changes between epithelial and mesenchymal states are important for the successful development of metastatic tumors (3). Understanding the relationship between these two events is not only scientifically interesting but also important for developing strategies to target metastatic cancers.

Metabolic rewiring allows uncontrolled proliferative cancer cells to meet their requirements for energy-demanding activities and macromolecule biosynthesis $(1,2)$. Cancer cells are dependent on exogenous nutrients because endogenous nutrients are insufficient to maintain their active proliferation (4-6). Blockage of cancer-specific metabolism retards tumor growth or induces cancer cell death through modulation of various signaling pathways (7-10). Compared to the extensive understanding of metabolic reprogramming during the carcinogenic process, knowledge about the metabolic changes of cancer cells in late-stage progression and metastasis is relatively limited. 
Epithelial-mesenchymal transition (EMT) is a process in which epithelial cells lose their intercellular adherence and cellular polarity and acquire the mesenchymal phenotype (11). EMT is a crucial mechanism for embryogenesis, organ fibrosis, and cancer metastasis (11). In cancer cells, activation of EMT leads cells to acquire migration, invasion, stemness, and drug resistance, whereas the reverse process of EMT, i.e., mesenchymal-epithelial transition (MET), is important for metastatic colonization (3). The updated concept suggests that dynamic changes between epithelial and mesenchymal phenotypes, i.e., epithelial-mesenchymal plasticity, rather than a fixed phenotype, are preferred for developing metastatic tumors, and a hybrid epithelial-mesenchymal state harbors a higher plasticity for metastasis (12).

Here, we will review the metabolic changes and current strategies for targeting cancer metabolism, epithelialmesenchymal plasticity, and the mutual influences between these two events. The impact of metabolic targeting on epithelial/mesenchymal phenotypes and metastasis will also be reviewed.

\section{METABOLIC REPROGRAMMING IN CANCER CELLS: MECHANISMS, BIOMARKERS, AND THERAPEUTIC TARGETING \\ Mechanism for Metabolic Changes in Cancer Cells}

Cells break down nutrients to generate energy and building blocks through metabolic pathways. Adenosine triphosphate (ATP), as the cellular energy currency, is generated by aerobic or anaerobic respiration. Cells take up glucose and convert it into pyruvate through glycolysis. Under normoxic environments, cells further convert pyruvate into acetyl coenzyme A (acetylCoA) in mitochondria, which provides an acetyl group to the tricarboxylic acid (TCA) cycle, a major reaction for energy generation. Under hypoxic conditions, cells convert pyruvate into lactate through anaerobic glycolysis. However, cancer cells produce lactate regardless of oxygen availability (13), and this phenomenon is called the Warburg effect or aerobic glycolysis $(14,15)$. Cancer cells generate ATP and glycolytic intermediates quickly through only 10 reaction steps within aerobic glycolysis compared to the highly complicated oxidative phosphorylation. ${ }^{18} \mathrm{~F}$-deoxyglucose-positron emission tomography confirmed the increased glucose uptake in tumors compared to normal tissues in cancer patients (16). Interestingly, cancer cells do not completely depend on aerobic glycolysis; instead, they also maintain functioning mitochondria and oxidative phosphorylation $(17,18)$. A possible explanation is that the mitochondrial electron transport chain generates high levels of reactive oxygen species (ROS) during oxidative phosphorylation of cancer cells. ROS activate signaling pathways to stimulate cancer cell proliferation (18). Cancer cells also generate high levels of nicotinamide adenine dinucleotide phosphate (NADPH) as an antioxidant in both the mitochondria and the cytosol to limit excessive ROS to prevent ROS-induced apoptosis
(19). Both the Warburg effect and oxidative phosphorylation generate sufficient energy and glycolytic carbon intermediates, which are essential for the synthesis of macromolecules to meet the requirements of highly proliferative cancer cells. In addition to the derangement of glucose metabolism, mutations of the key enzymes in TCA cycle/glucose metabolism have been identified in human cancers. Isocitrate dehydrogenase (IDH) includes three main isoforms. IDH3 is the main isoform in the TCA cycle that catalyzes the irreversible conversion of isocitrate to $\alpha$-ketoglutarate in the mitochondria and generates $\mathrm{NADH}$. IDH1 and IDH2 generate NADPH by catalyzing the reversible isocitrate-to- $\alpha$-ketoglutarate conversion in the cytoplasm and the mitochondria, respectively. Mutations of IDH1 and IDH2 have been recognized as oncogenic events through decreasing $\alpha$-ketoglutarate and increasing $\mathrm{D}$ 2-hydroxyglutarate production (20), and the neomorphic IDH mutant has been shown in acute myeloid leukemia (21) and gliomas (22).

In addition to aerobic glycolysis, there are several major metabolic derangements noted in cancer cells. The pentose phosphate pathway (PPP) is recognized as an important pathway for catabolizing glucose in cancer cells. The PPP is important because it not only utilizes glucose for energy but also maintains the biosynthesis of lipids and nucleotides and the antioxidant responses of cancer cells (23). Furthermore, reprogramming of lipid metabolism is an important feature of cancer cells. Oxidation and synthesis of lipids support cancer cell proliferation by providing building blocks for membrane synthesis and additional energy sources (24). Fatty acids are mostly obtained from environmental sources in normal cells; in contrast, de novo synthesis of fatty acids is frequently increased in cancer cells (25). Another well-recognized metabolic alteration in cancer cells is glutamine dependency. Glutamine not only provides an important metabolite in the TCA cycle ( $\alpha$-ketoglutarate by glutaminase) (26) but also provides the nitrogen building blocks for nucleotide and amino acid synthesis (2).

Deregulation of nucleotide metabolism, especially ATP, has also been noted as a major event in cancer metabolism, and it mainly influences antitumor immunity. High levels of extracellular ATP generation are induced by inflammation, ischemia, or hypoxia within tumor microenvironments through various pathways, including channel or transporter-mediated release, vesicular exocytosis, or direct release due to cell destruction (27). Extracellular ATP is sequentially converted to adenosine monophosphate (AMP), and AMP is hydrolyzed to adenosine through ectonucleotidase CD39- and CD73-mediated dephosphorylation (28). Adenosine is not only involved in cancer growth but also generates anti-inflammatory responses by modulating various cells in the tumor microenvironment, such as endothelial cells, mast cells, natural killer cells, neutrophils, macrophages, dendritic cells, and lymphocytes (29). In addition, adenosine stimulates the differentiation of naive $\mathrm{CD} 4{ }^{+} \mathrm{CD} 25^{-} \mathrm{T}$ cells to $\mathrm{CD} 4{ }^{+} \mathrm{CD} 25^{+}$Foxp $^{+}$regulatory $\mathrm{T}$ cells and induces $\mathrm{T}$ cell anergy (30). Notably, HIF- $1 \alpha$ induced by the hypoxic tumor microenvironment enhances the expression of adenosinergic molecules, including CD39 and CD73, as well as the adenosine 2B receptor (A2BR) $(31,32)$. Overexpression of these adenosinergic 
molecules is associated with metastasis and poor patient outcomes in different cancers $(28,33)$.

Thus, the metabolic reprogramming of cancer cells includes aerobic glycolysis, the PPP, lipid metabolism changes, glutaminolysis, nucleotide metabolism, and many other events. These adaptive changes provide sufficient energy for sustaining cancer cell proliferation, providing building blocks for macromolecule synthesis, and suppressing antitumor immunity for immune evasion.

\section{Therapeutic Targeting for Cancer Metabolism}

Canonical cancer treatments preferentially target proliferationrelated pathways with unavoidable toxicity to proliferating normal cells such as intestinal crypt cells, hematopoietic cells, and hair follicle cells. In addition, certain normal cells exhibit a higher proliferation rate than cancer cells (34). Targeting tumor-specific metabolism is therefore an attractive strategy for anticancer treatment. However, the complex crosstalk between tumor cells and the microenvironments substantially increases the difficulty of specific targeting of cancer metabolism. For example, lactate produced by cancer cells shuttles not only to neighboring cancer cells but also to the surrounding stromal cells and vascular endothelial cells (35). Here, we review the recent progress in targeting cancer metabolism, including the amino acid catabolism and the metabolism of lipids and glucose. Preclinical and clinical studies targeting cancer metabolism are summarized in Table $\mathbf{1 .}$

\section{AMINO ACID METABOLISM}

\section{Glutamine}

Glutamine addiction has been extensively found in cancer cells (61). Glutamine is involved in various metabolic processes of cancer cells: glutamine acts as a nitrogen donor for nucleic acid and amino acid biosynthesis, drives oxidative phosphorylation and is the substrate for lipid and glutathione synthesis (62). Moreover, Muir et al. showed that glutamine is probably a more important substrate in vitro in cell culture than in vivo (63). There are two strategies for targeting glutamine metabolism in cancer cells: inhibition of glutaminase that can convert glutamine into glutamate and blockage of the major glutamine transporter alanine-serine-cysteine transporter 2 (ASCT2) to suppress the influx of glutamine into the cancer cells $(64,65)$. Inhibition of the glutaminase GLS1 and GLS2 either alone or in combination with other therapies enhanced the antitumor effects in preclinical studies $(36,37,66-68)$. The tolerability and promising antitumor efficacy of the GLS1 small molecular inhibitor CB-839 combined with the vascular endothelial growth factor receptor (VEGFR)/MET inhibitor cabozantinib have been demonstrated in phase I/II clinical trials for patients with metastatic renal cell carcinoma (38-40). Overexpression of ASCT2 has been shown in various cancer types, including lung cancer (41), breast cancer (69), colorectal cancer (70), prostate cancer (71), and melanoma (72). Blockage of ASCT2 via monoclonal antibodies inhibits glutamine-dependent colorectal cancer cell growth in vitro and in vivo (42).

\section{Asparagine}

Asparagine bioavailability significantly influences the metastatic potential of cancer cells. Asparagine serves as an essential amino acid for protein synthesis to adapt to the relatively low levels of extracellular glutamine in cancer cells (73). Suppression of the bioavailability of asparagine through dietary restriction or L-asparaginase, which catalyzes the hydrolysis of asparagine to aspartic acid and ammonia, suppresses breast cancer metastasis (43). L-asparaginase administration has been extensively used in treating acute lymphoblastic leukemia (ALL) because ALL cells cannot synthesize adequate levels of asparagine and highly depend on exogenous asparagine to maintain cell growth $(44,45)$. However, intolerable toxicities have been reported in patients treated with L-asparaginase in different clinical trials $(74,75)$, which may limit the clinical application of L-asparaginase in the treatment of solid tumors.

\section{Arginine}

Arginine plays a crucial role in major physiological events, including cell proliferation, cell signaling, nitric oxide synthesis, and T-cell functions (76). Cancer cells are unexpectedly dependent on arginine for their growth, and depletion of arginine induced cancer cell death and tumor suppression in preclinical studies (77). Reduced expression of arginosuccinate synthase 1 (ASS1) has been observed in melanoma, glioma, lymphoma, and prostate cancer (78), and arginine deprivation therapy may generate antitumor efficacy in these cancer cells due to ASS1involved arginine synthesis. A pegylated recombinant human arginase polyethylene glycol (PEG)-BCT-100 depleted systemic arginine. In advanced hepatocellular carcinoma (HCC) patients, PEG-BCT-100 demonstrated its safety and efficacy in a phase I trial (46). However, another arginine depletion therapy by administration with pegylated arginine deiminase ADI-PEG 20 as the second-line monotherapy in advanced HCC patients did not show a survival benefit in the phase III trial (47). In addition to cancer metabolism mediated by arginine, arginine is also involved in the immune escape of cancer cells (79) and immunomodulation of macrophages (80). Arginine deprivation therapy in combination with immunotherapy may be a rational modality for cancer treatment in the future.

\section{NUCLEOTIDE METABOLISM}

Adenosinergic molecules have been shown to activate immunosuppressive signals in tumor microenvironments. Inhibition of adenosinergic molecules is therefore a promising strategy for cancer treatment. Preclinical data showed that using the $\mathrm{B} 7-\mathrm{DC} / \mathrm{Fc}$ fusion protein significantly improves the antitumor immune response in adenosine $A_{2 A}$ receptor (A2AR) knockout mice (81). The A2AR inhibitor SCH58261 combined with the anti-CD73 monoclonal antibody TY/23 generated synergistic antitumor effects and reduced cancer metastasis in a syngeneic mouse tumor model (48). A human monoclonal antiCD73 antibody, MEDI9447, has been developed for anticancer treatment (49). The oral A2AR inhibitor CPI-444 in combination with immune checkpoint blockades, such as antibodies against 
TABLE 1 | Developing treatments for targeting cancer metabolism.

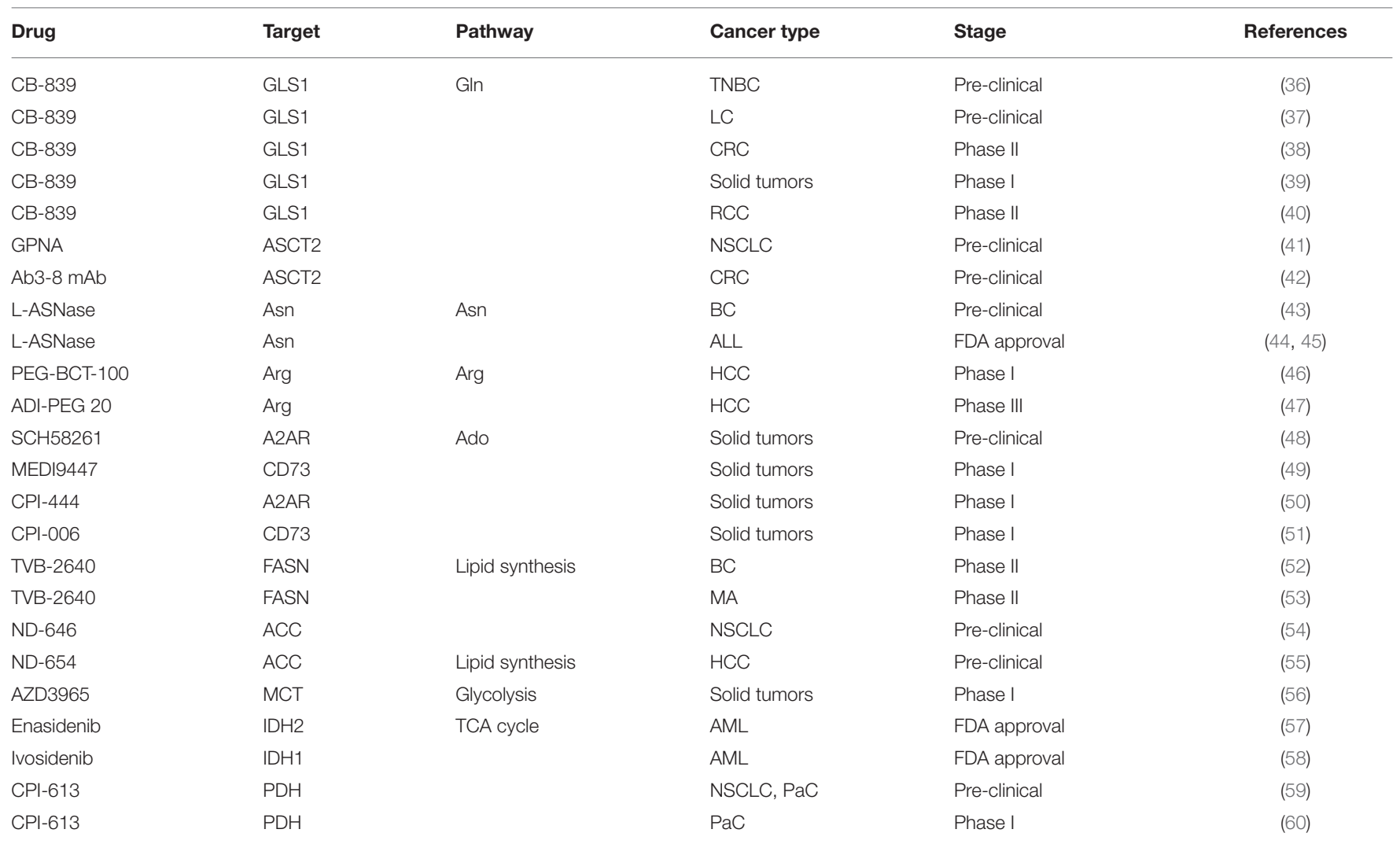

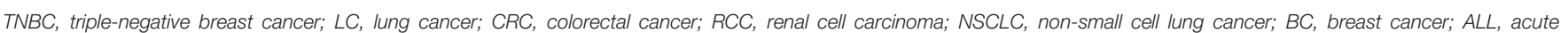

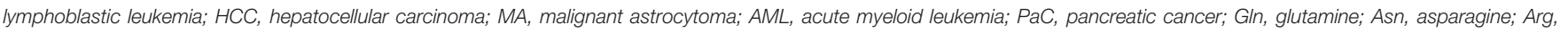
arginine; Ado, adenosine.

programmed death 1 (PD-1) or cytotoxic T-lymphocyteassociated protein-4 (CTLA-4), generated synergistic antitumor effects and significant tumor regression and led to memory antitumor immune responses in preclinical studies (82). The safety and tolerability of CPI-444 alone or in combination with the anti-programmed death ligand 1 (PD-L1) antibody atezolizumab have been investigated in phase I clinical trials (50). The safety and efficacy of the humanized anti-CD73 monoclonal antibody CPI-006 administered alone or in combination with CPI-444 or pembrolizumab were studied in phase I clinical trials for advanced cancers (51).

\section{LIPID METABOLISM}

Endogenous fatty acid production is partially mediated by increased glycolytic metabolites in cancer cells (83). Frequent alterations of fatty acid synthase (FASN), a crucial metabolic multienzyme complex that is involved in the final process of fatty acid synthesis, have been revealed in various malignancies (84). FASN inhibition was proposed to induce antitumor activity by regulating apoptosis, cell membrane integrity, DNA replication (85), and Akt signaling $(86,87)$. The oral FASN inhibitor TVB-2640 combined with different cancer treatments has been assessed in clinical trials, including combined paclitaxel and trastuzumab for human growth factor receptor-2 (HER2)positive advanced breast cancer (52), combined paclitaxel for patients with heavily pretreated breast cancer, and combined bevacizumab for high-grade astrocytoma (53). Acetyl-CoA carboxylase (ACC) catalyzes the rate-limiting step of fatty acid synthesis by carboxylation of acetyl-CoA to malonylCoA. Preclinical data showed that an inhibitor of ACC ND646 administered alone or in combination with carboplatin exhibits antitumor efficacy in non-small cell lung cancerbearing mice (54). Another liver-specific ACC inhibitor, ND654 , used alone or in combination with the multikinase inhibitor sorafenib, inhibited lipogenesis and cancer development in HCCbearing rats (55). The antitumor efficacy of the lipid synthesistargeting agents ND-646 and ND-654 are under investigation in clinical trials.

\section{TCA CYCLE AND GLUCOSE METABOLISM}

The mutant $I D H 2$ inhibitor enasidenib has been approved by the U.S. Food Drug Administration (FDA) for the treatment of mutant $I D H 2$ recurrent or refractory acute myeloid leukemia (AML) (57). Furthermore, another mutant IDH1 inhibitor, ivosidenib, was approved by the U.S. FDA for the treatment of mutant IDH1 relapsed or refractory AML (58). Lipoate 
(lipoamide) is a cofactor that acts collaboratively with pyruvate dehydrogenase $(\mathrm{PDH})$ and the $\alpha$-ketoglutarate dehydrogenase $(\mathrm{KGDH})$ complex in the TCA cycle. Elevated lipoate induces functional impairment of $\mathrm{PDH}$ through phosphorylation of $\mathrm{PDH}$, which blocks the mitochondrial entrance of pyruvate to disrupt the TCA cycle (88). The small molecule lipoate analog CPI-613 not only inhibited the activities of PDH and $\mathrm{KGDH}$ but also exhibited antitumor effects in preclinical settings $(59,89)$. A phase I clinical trial showed that CPI-613 combined with chemotherapy maximizes the tolerated dose in patients with metastatic pancreatic cancer in a phase I clinical trial (60). Acidic tumor microenvironments caused by aerobic glycolysis are associated with metastasis, angiogenesis, and drug resistance (90). Targeting lactate through its transport, named monocarboxylate transporter (MCT), including MCT-1 and MCT-4 isoforms that are frequently expressed in cancer cells (91-94), is an anticancer strategy mediated through regulating the influx and efflux of lactate. The MCT-1 inhibitor AZD3965 combined with doxorubicin or rituximab showed synergistic antitumor efficacy in lymphoma in vitro (95). AZD3965 exhibited good tolerability and promising efficacy in preclinical studies and early-phase clinical trials of patients with advanced solid tumors (56).

\section{Applications of Cancer Metabolism as a Biomarker}

The development of biomarkers for cancer metabolism is important for prognostication and assessment of metabolismtargeting treatment responses. However, the available metabolism-related markers are limited. Neomorphic IDH mutants are oncogenic drivers for generating the oncometabolite 2-hydroxyglutarate in AML and gliomas $(21,22)$. Recently, two mutant IDH inhibitors, enasidenib (AG-221) and ivosidenib (AG-120), have been approved for IDH-mutant refractory AML $(57,58) . I D H$ mutation is therefore a biomarker for selecting IDH inhibitors. Another example is the KEAP1 mutation as the biomarker for glumaminolysis inhibitors. Approximately $20 \%$ of KRAS-mutant non-small cell lung cancers carry lossof-function mutations of the KEAP1 gene (96). The major target of KEAP1 is Nrf2, which triggers antioxidative stress genes to endure oxidative stress (97). Enhanced Nrf2 activities further trigger the transcription of genes encoding antioxidants, drug pumping proteins, and other metabolic enzymes (98). In addition, increased glutamine addiction in cancer cells activates Nrf2. In a KRAS-mutant lung cancer mouse model, KEAP1 or Nrf2 mutations increased the sensitivity of glutaminase inhibitors (99). KEAP1 mutation may be considered a potential biomarker for anti-glutamine treatment. A further example is the application of the hexokinase isoform as a prognostic marker. The glycolytic enzyme hexokinase catalyzes glucose to glucose-6phosphate, and high levels of hexokinase are expressed in cancer cells to accelerate glucose metabolism (100). Hexokinase isoform 2 has been identified as a prognostic biomarker in HCC, gastric cancer, and colorectal cancer (101).

In summary, deregulation of metabolism is important for cancer cells to adapt to rapid proliferation-induced environmental stress. Targeting cancer-specific metabolism is a promising therapeutic strategy, and future development of biomarkers for guiding this treatment is mandatory.

\section{EPITHELIAL-MESENCHYMAL PLASTICITY IN CANCER PROGRESSION}

\section{Mechanism of EMT}

In cancer metastasis, primary cancer cells acquire a mesenchymal phenotype to exhibit enhanced migration, invasion, and metastasis (102). In metastatic sites, tumor cells regain the epithelial phenotype for colonization to form secondary tumors via mesenchymal-epithelial transition (MET) (103). The expression levels of epithelial markers such as E-cadherin, epithelial cell adhesion molecule (EpCAM), cytokeratin, and occludin and mesenchymal markers including $\mathrm{N}$-cadherin and vimentin are used to define the epithelial/mesenchymal status (104). We recently demonstrated that cancer cells in the intermediate status of EMT exhibit more aggressive properties to form collective cancer clusters to overcome stressful environments during metastasis (105).

EMT is regulated by multiple signaling networks via regulation at the levels of transcription, epigenetic regulation, translation, and post-translation (106). EMT transcription factors (EMT-TFs), including Snail, Twist1/Twist2, and the zinc finger E-box-binding homeobox (ZEB) families, are the major regulators of EMT (107). EMT-TFs act as transcriptional repressors to suppress the expression of epithelial genes; in addition, they act as activators to induce the transcription of mesenchymal and other metastasis-related genes (108). For example, Snail is a transcriptional repressor that induces EMT by suppressing E-cadherin. We showed that CREB-binding protein (CBP) acetylates Snail. Acetylation of Snail prevents the formation of a repressive complex and switches Snail from a repressor to an activator (109). Similarly, the bifunctional switch is also demonstrated in another important EMT transcriptional factor (EMT-TF), zinc finger E-box-binding homeobox 1 (ZEB1): it acts as a repressor of E-cadherin by binding to the E-boxes located at the $C D H 1$ promoter (110). The interaction between the ZEB1 and Smad proteins and p300 also changes ZEB1 to an activator $(111,112)$.

In addition to transcriptional control, epigenetic regulation of epithelial and mesenchymal genes is crucial for providing plasticity and dynamic changes between epithelial and mesenchymal states. Snail recruits polycomb repressive complex 2 (PRC2) to repress $\mathrm{CDH} 1$ expression by enriching the repressive mark $\mathrm{H} 3 \mathrm{~K} 27 \mathrm{me} 3$ on the regulatory region (113). We demonstrated that Twistl interacts with the polycomb repressive protein Bmil to act coordinately for EMT induction through suppression of CDH1 and P16INK4A (114). MicroRNAs (miRNAs) are also involved in EMT by selectively suppressing the mRNAs of EMT-TFs by cleavage-mediated degradation or translational repression (115). The reciprocal regulation between ZEB1 and miR-200 family miRNAs plays an important role in maintaining epithelial-mesenchymal plasticity (116). The major external stimuli of EMT in cancer cells include 
TGF- $\beta$ and hypoxic conditions. TGF- $\beta$ is the best-known inducer that activates EMT-TFs to induce EMT $(117,118)$. We previously revealed that intratumoral hypoxia caused by the rapid proliferation of tumor cells activates EMT through the directional regulation of Twist1 by hypoxia inducible factor- $1 \alpha$ $($ HIF-1 $\alpha)(119)$.

\section{Functional Role of EMT in Metastasis and Treatment Resistance}

Regarding the functional impacts of EMT on cancer cells, EMT induces stem-like properties (120) and enhances resistance to chemotherapy (3). Enriched cancer stem cells (CSCs) are shown in murine or human breast tumors with high expression of EMT-TFs (121). In colorectal cancers, we showed that Snail not only upregulates interleukin-8 (IL-8) to induce CSC formation (122) but also promotes the asymmetrical cell division-tosymmetrical cell division switch for expanding CSC pools (123). Both Snail and Twist 1 conferred chemoresistance in a genetically engineered mouse model of pancreatic cancer (124). Twist1 and ZEB are commonly expressed in chemoresistant triplenegative breast cancers (125). Snail contributes to cisplatin resistance by upregulating the DNA repair protein excision repair cross complementation group 1 in head and neck cancer (126). Various EMT signatures have been shown to predict resistance to epidermal growth factor receptor (EGFR) or phosphatidylinositol 3-kinase (PI3K) inhibitors in clinical samples and cell lines derived from non-small-cell lung cancer patients (127). In summary, dynamic changes between epithelial and mesenchymal states are crucial for metastasis and the malignant characteristics of cancer cells, such as cancer stemness and therapeutic resistance.

\section{Feasibility of EMT as a Therapeutic Target and Biomarker}

EMT is an attractive target for antimetastatic therapy owing to the significant contribution of EMT to metastasis (128). However, inhibiting EMT may simultaneously promote MET, which is a crucial step for metastatic colonization. Ideally, specific killing of metastatic mesenchymal-type cancer cells will be effective; however, extensive drug resistance has been noted in these cells. In addition, distinct mechanisms for inducing EMT hinder the development of anti-EMT therapy. Theoretically, anti-EMT therapies include precise targeting of mesenchymaltype cancer cells and reversing EMT/transdifferentiation of EMT cancer cells into innocuous cells (128). Direct targeting of EMT-undergoing cancer cells is relatively difficult because drug resistance frequently exists in EMT cancer cells, and EMT-TFs are mostly undruggable. An alternative approach to intercept EMT is to target the downstream signals of EMT. For example, miR-200 family microRNAs downregulate the metastasis-inhibiting secretory protein tubulointerstitial nephritis antigen-like 1 (Tinagl1) during MET. Treatment with recombinant Tinagl1 suppressed triple-negative breast cancer progression and metastasis (129).

EMT-induced mesenchymal markers on circulating tumor cells (CTCs) are also potential biomarkers for cancer metastasis
(130). For example, cell-surface vimentin (CSV) is detected on CTCs from the blood of patients with metastatic colon cancer. CSV expression is significantly higher in metastatic tumors than in primary tumors, implying that CSV expression is correlated with colon cancer metastasis and could serve as a metastatic biomarker (131). CSV-positive CTCs also serve as a diagnostic and prognostic biomarker in pancreatic cancer (132). Moreover, the other EMT-induced CTC marker, plastin3 (PLS3), which acts as an actin-bundling protein known to inhibit cofilin-mediated depolymerization of actin fibers, is a prognostic biomarker in colorectal cancer (133) and breast cancer (134). Recently, EMT has also been associated with the immunosuppressive tumor microenvironment (135) and thus has become a potential biomarker to predict the responses to PD-1/PD-L1 blockade immunotherapy (136).

Together, anti-EMT therapies should be rationally combined with other modalities of cancer treatments to maximize antitumor efficacy. Identification of more druggable targets of EMT as cancer therapeutics will be mandatory for the development of anti-EMT treatment.

\section{INTERPLAY BETWEEN CANCER METABOLISM AND EPITHELIAL-MESENCHYMAL PLASTICITY}

\section{Evidence of Their Mutual Influences}

Accumulating evidence indicates the distinct energy requirements in different steps of metastasis. A favorable reprogramming of metabolism has been noted to provide a survival advantage for metastatic cancer cells such as CTCs by prioritizing energy production (102). Adaptation of metabolism was shown to modulate cancer cell motility through mitochondrial regulation (137) as well as detachment of cancer cells from the extracellular matrix (138) and invasion (139). The major EMT inducer transforming growth factor$\beta$ (TGF- $\beta$ ) also affects various cancer metabolic processes, such as glycolysis, mitochondrial respiration, and lipid metabolism $(117,118)$. The major metabolic changes of the different epithelial/mesenchymal states can be summarized as several categories, including mitochondrial dynamics, lipid metabolism, and the influence of cell-matrix interactions on energy production. Figure 1 summarizes the major metabolic events in different epithelial-mesenchymal states of cancer cells.

The maintenance of mitochondrial morphology is balanced by mitochondrial fission and fusion (140-142). Fragmented mitochondrial formation is mediated by either enhanced mitochondrial fission or repressed mitochondrial fusion through fission or mitofusin-related proteins, respectively. Epithelial or mesenchymal cells display distinct mitochondrial morphologies that regulate their mitochondrial function for cellular proliferation. In epithelial-type cancer cells, the mitochondrial fission protein dynamin-related protein 1 (DRP1) mediates fragmented mitochondria $(141,143)$ and impaired oxidative phosphorylation $(144,145)$. Recently, $\mathrm{Wu}$ et al. demonstrated that Snail and TGF- $\beta$ direct mesenchymal cells to display fused/tubulated mitochondria via activation of the 


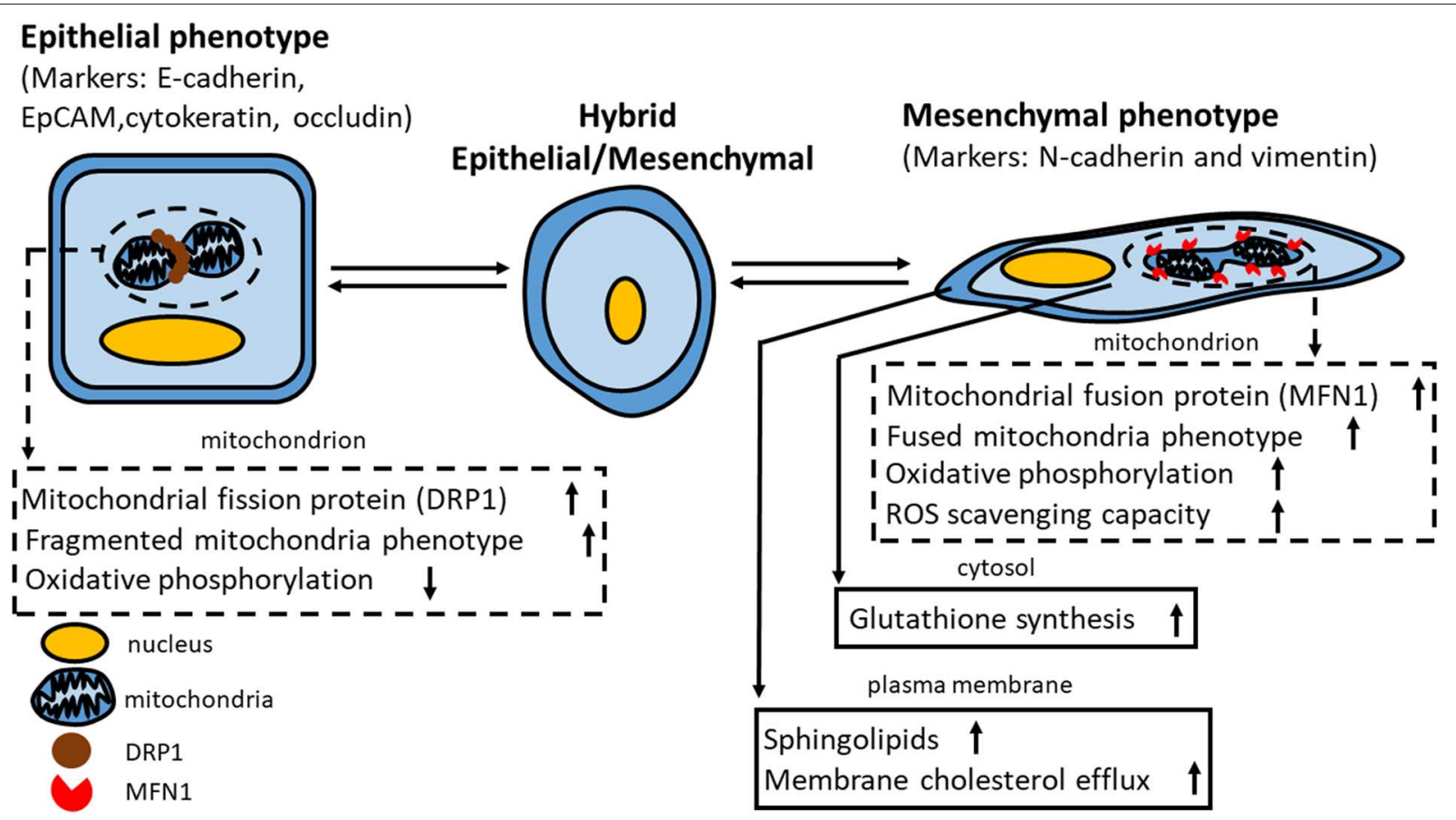

FIGURE 1 | Correlation between cancer metabolism and epithelial-mesenchymal plasticity. The schema presents the differential characteristics of metabolism in cancer cells in the epithelial, mesenchymal, and hybrid states. MFN1, mitofusin-1; ROS, reactive oxygen species; DRP1, dynamin-related protein-1. Please note that the size of mitochondria is disproportionately magnified for presenting the molecular events in epithelial/mesenchymal states.

mitochondrial fusion protein mitofusin-1 (MFN1), which enhances glutathione synthesis and the ROS scavenging capacity in mammary stem cells (137). Together, fused mitochondria are associated with increased oxidative phosphorylation and the TCA cycle $(146,147)$, and a reversal of the EMT phenotype is correlated with decreased fused mitochondria with impaired mitochondrial function (137).

TGF- $\beta 1$ induces EMT in cancer cells through the induction of EMT-TFs such as Snail $(117,118)$. In addition to inducing EMT-TFs, TGF- $\beta 1$ directs the metabolic switch from glycolysis to oxidative phosphorylation through suppression of pyruvate dehydrogenase kinase 4 , which acts as a checkpoint of TCA cycle entry by repressing the activity of pyruvate dehydrogenase (148). In addition, TGF- $\beta 1$-induced EMT and metastasis suppress lipogenesis and enhance oxidative phosphorylation in lung cancer (149). Cancer cell migration, invasion, and metastasis enhance oxidative phosphorylation and mitochondrial biogenesis mediated by upregulation of the transcriptional coactivator peroxisome proliferator-activated receptor gamma coactivator 1 alpha (PGC-1 $\alpha$ ) in breast cancer (150). However, contradictory studies have shown that Snail facilitates glucose uptake, macromolecule biosynthesis, and respiration inhibition by repressing fructose-1,6-bisphophatase 1 in basal-like breast cancer (151). In addition, Snail was shown to promote glycolytic metabolism by inhibiting phosphofructokinase (152) or cytochrome C oxidase (153) in breast cancer. Therefore, the role of EMT in regulating cancer metabolism is still controversial.
Metastatic cancer cells acquire their motile and invasive capacity to detach from primary tumors, enter into and leave the bloodstream, and colonize to form metastatic tumors. Metabolic alterations of lipids have been shown to be involved in these processes. Alterations of structural components of the cell membrane, including lipid rafts, cholesterol, and sphingolipids, together with regulators of cellular motility/invasiveness, such as CD44, extracellular matrix (ECM) as a degraded non-cellular structure, and invadopodia formation enhance cancer cell motility (154). High levels of cholesterol in membranes impede cellular fluidity and subsequently decrease metastasis by limiting cell motility during EMT and intra/extravasation (155). Cancer cells upregulate the ATP-binding cassette transporter ABCA1 to increase cholesterol efflux, and overexpression of ABCA1 in human cancers increases metastasis (155). Sphingolipids enhance EMT (156) and the motile phenotype (157, 158) by modulating sphingosine-1-phosphate receptor-dependent or receptor-independent signaling pathways in cancer cells. In addition, various enzymes of lipid metabolism are involved in EMT of cancer cells (159). For instance, the lipogenic enzyme ATP-citrate lyase (ACLY) has been shown to interact with the low molecular weight isoform of cyclin $\mathrm{E}$ to promote the transformation, migration and invasion of breast cancer cells (160).

The absence of cell-matrix interactions induces a type of programmed cell death, anoikis (161), which occurs during the detachment of non-hematopoietic cells from the ECM due to insufficient glucose uptake-induced shortage of ATP 
(162). In contrast, CTCs rewire their metabolism not only to prevent anoikis but also to enhance the acquisition of anchorage independence during metastatic dissemination (163, 164). CTCs diminish the levels of ROS caused by ECM detachment to evade anoikis $(162,165)$. In lung cancer cells, the detachment process suppresses both cell growth pathways and carboxylation of cytosolic $\alpha$-ketoglutarate and then induces citrate into mitochondria to further enhance NADPH production to relieve oxidative stress (166). Elevated ROS levels are also found in melanoma CTCs compared to their primary tumors. To withstand oxidative stress, metastatic melanoma cells undergo reversible metabolic alterations to enhance NADPH-generating enzymes through the folate pathway (167). Together, alterations of cell-matrix interactions increase the oxidative stress of metastatic cancer cells. Cancer cells undergo metabolic reprogramming to overcome oxidative stress to sustain survival.

\section{Potential Therapies for Intercepting EMT Through Metabolic Targeting}

EMT is highly associated with cancer metastasis through alterations of multiple crucial events, including metabolic rewiring (168). For amino acid metabolism, cancer cells mainly utilize glutamine to synthesize nucleotides and nonessential amino acids as well as to provide substrates for the TCA cycle (34). Glutamine metabolism has been reported to regulate EMT. Inhibition of glutaminolysis, the deamination process of glutamine into glutamate, by targeting glutaminase GLS1 alleviates cancer metastasis by suppressing Snail in lung cancer (169). The mitochondrial isoform of glutaminase GLS2 inhibits migration, invasion, and metastasis through repression of Snail in HCC (170). These findings suggest that targeting glutaminase in cancer cells not only blocks glutamine addiction but also suppresses EMT.

Cancer cells increase lipogenesis and lipolysis to rewire lipid metabolism. The fatty acid synthetic enzyme FASN induces EMT by enhancing TGF- $\beta$ expression in non-small cell lung cancer (171). In addition, EMT promotes FASN expression. FASN and EMT are reciprocally and coordinately upregulated in non-small cell lung cancer (171). The FASN inhibitor TVB-2640 may inhibit tumor growth and metastasis, and the efficacy is under evaluation in clinical trials. In addition, peroxisome proliferator-activated receptor (PPAR) family members, regulators of fatty acid synthesis and oxidation, are involved in lipid synthesis or degradation as well as EMT inhibition (172). Pharmacological and genetic inhibition of $\mathrm{PPAR} \beta / \delta$ increased metastasis through EMT induction in melanoma (172). Moreover, PPAR $\gamma$ knockout induced both EMT and stemness in prostate cancer (173). These studies indicate that targeting $\mathrm{PPAR} \beta / \delta$ or $\gamma$ may have potential clinical applications for the treatment of cancer patients by reducing metastasis. In addition to the FASN and PPAR members, a membranous lipid with a sphingosine backbone, sphingolipid, as described earlier, is also involved in EMT induction by regulating sphingosine kinase 1 (SPHK1), which converts sphingosine into sphingosine 1-phosphate (S1P) $(174,175)$ in cancers. SPHK1 has been reported to induce EMT through autophagic degradation of Ecadherin (176) or activation of focal adhesion kinase (177) in HCC or colorectal cancer, respectively. S1P has a role in EMT induction via the matrix metalloproteinase-7 (MMP-7)/TGF$\beta$ autocrine loop in HCC (178). Therefore, SPHK1 and S1P may serve as promising therapeutic targets to alleviate EMTmediated metastasis by disrupting sphingolipid metabolism in cancers.

In glucose metabolism, cancer cells increase glucose uptake and glycolysis flux, mitochondrial dysfunction, or the acidic tumor microenvironment to promote progression. For example, MMP-2 expression is increased by the major glucose transporter GLUT1 to further enhance EMT and invasion in cancer cells $(179,180)$. Consequently, cancerspecific GLUT1 targeting may reduce metastasis in cancers. In summary, EMT-mediated cancer metastasis may be attenuated by targeting cancer metabolites, including amino acids, lipids, and glucose, as a potential alternative anti-cancer modality.

\section{CONCLUSIONS}

Metabolic reprogramming and epithelial-mesenchymal plasticity are the major adaptive strategies of cancer cells to endure rapid proliferation and metastasis-related environmental stress. Understanding the dynamic changes of the epithelial and metabolic states during the metastatic process is essential for developing optimal strategies to target disseminated cancers. Although a growing number of drugs have been developed to target cancer-specific metabolism, there are still issues that must be addressed before wide application of this treatment. Discovery of biomarkers for guiding antimetabolic treatment and elucidation of the interplay between metabolism and EMT to prevent metabolic change-induced adverse events will be important for the treatment of highly dynamic metastatic cancers.

\section{AUTHOR CONTRIBUTIONS}

$\mathrm{N}-\mathrm{YS}$ and M-HY wrote the manuscript and approved the final version.

\section{FUNDING}

This work was supported by the Ministry of Science and Technology (MOST 108-2314-B-010-020-MY3 and MOST-108-2320-B-010-008), the Featured Areas Research Center Program within the framework of the Higher Education Sprout Project by the Ministry of Education, and the Center of Excellence for Cancer Research granted from the Ministry of Health and Welfare (MOHW109-TDU-B-211-134019). 


\section{REFERENCES}

1. Hanahan D, Weinberg RA. Hallmarks of cancer: the next generation. Cell. (2011) 144:646-74. doi: 10.1016/j.cell.2011.02.013

2. Pavlova NN, Thompson CB. The emerging hallmarks of cancer metabolism. Cell Metab. (2016) 23:27-47. doi: 10.1016/j.cmet.2015.12.006

3. Nieto MA, Huang RY, Jackson RA, Thiery JP. EMT: 2016. Cell. (2016) 166:21-45. doi: 10.1016/j.cell.2016.06.028

4. Yamamoto T, Takano N, Ishiwata K, Ohmura M, Nagahata Y, Matsuura $\mathrm{T}$, et al. Reduced methylation of PFKFB3 in cancer cells shunts glucose towards the pentose phosphate pathway. Nat Commun. (2014) 5:3480. doi: $10.1038 /$ ncomms 4480

5. Vander Heiden MG. Targeting cancer metabolism: a therapeutic window opens. Nat Rev Drug Discov. (2011) 10:671-84. doi: 10.1038/nrd3504

6. Ward PS, Thompson CB. Metabolic reprogramming: a cancer hallmark even warburg did not anticipate. Cancer Cell. (2012) 21:297-308. doi: 10.1016/j.ccr.2012.02.014

7. Qie S, Liang D, Yin C, Gu W, Meng M, Wang C, et al. Glutamine depletion and glucose depletion trigger growth inhibition via distinctive gene expression reprogramming. Cell Cycle. (2012) 11:3679-90. doi: 10.4161/cc.21944

8. Agrawal V, Alpini SE, Stone EM, Frenkel EP, Frankel AE. Targeting methionine auxotrophy in cancer: discovery and exploration. Expert Opin Biol Ther. (2012) 12:53-61. doi: 10.1517/14712598.2012.636349

9. Gelb T, Pshenichkin S, Rodriguez OC, Hathaway HA, Grajkowska E, DiRaddo JO, et al. Metabotropic glutamate receptor 1 acts as a dependence receptor creating a requirement for glutamate to sustain the viability and growth of human melanomas. Oncogene. (2015) 34:271120. doi: 10.1038/onc.2014.231

10. Cetinbas N, Daugaard M, Mullen AR, Hajee S, Rotblat B, Lopez A, et al. Loss of the tumor suppressor hacel leads to ROS-dependent glutamine addiction. Oncogene. (2015) 34:4005-10. doi: 10.1038/onc.2014.316

11. Greenburg G, Hay ED. Epithelia suspended in collagen gels can lose polarity and express characteristics of migrating mesenchymal cells. J Cell Biol. (1982) 95:333-9. doi: 10.1083/jcb.95.1.333

12. Williams ED, Gao D, Redfern A, Thompson EW. Controversies around epithelial-mesenchymal plasticity in cancer metastasis. Nat Rev Cancer. (2019) 19:716-32. doi: 10.1038/s41568-019-0213-x

13. Warburg O. On the origin of cancer cells. Science. (1956) 123:30914. doi: $10.1126 /$ science.123.3191.309

14. Lunt SY, Vander Heiden MG. Aerobic glycolysis: meeting the metabolic requirements of cell proliferation. Annu Rev Cell Dev Biol. (2011) 27:44164. doi: 10.1146/annurev-cellbio-092910-154237

15. Koppenol WH, Bounds PL, Dang CV. Otto Warburg's contributions to current concepts of cancer metabolism. Nat Rev Cancer. (2011) 11:32537. doi: $10.1038 / \mathrm{nrc} 3038$

16. Groves AM, Win T, Haim SB, Ell PJ. Non-[18F]FDG PET in clinical oncology. Lancet Oncol. (2007) 8:82230. doi: 10.1016/S1470-2045(07)70274-7

17. Tan AS, Baty JW, Dong LF, Bezawork-Geleta A, Endaya B, Goodwin J, et al. Mitochondrial genome acquisition restores respiratory function and tumorigenic potential of cancer cells without mitochondrial DNA. Cell Metab. (2015) 21:81-94. doi: 10.1016/j.cmet.2014. 12.003

18. Weinberg F, Hamanaka R, Wheaton WW, Weinberg S, Joseph J, Lopez $\mathrm{M}$, et al. Mitochondrial metabolism and ROS generation are essential for Kras-mediated tumorigenicity. Proc Natl Acad Sci USA. (2010) 107:878893. doi: 10.1073/pnas.1003428107

19. Anastasiou D, Poulogiannis G, Asara JM, Boxer MB, Jiang JK, Shen $\mathrm{M}$, et al. Inhibition of pyruvate kinase M2 by reactive oxygen species contributes to cellular antioxidant responses. Science. (2011) 334:127883. doi: 10.1126/science.1211485

20. Ward PS, Patel J, Wise DR, Abdel-Wahab O, Bennett BD, Coller $\mathrm{HA}$, et al. The common feature of leukemia-associated IDH1 and IDH2 mutations is a neomorphic enzyme activity converting alpha-ketoglutarate to 2-hydroxyglutarate. Cancer Cell. (2010) 17:225-34. doi: 10.1016/j.ccr.2010.01.020
21. Mardis ER, Ding L, Dooling DJ, Larson DE, McLellan MD, Chen K, et al. Recurring mutations found by sequencing an acute myeloid leukemia genome. N Engl J Med. (2009) 361:1058-66. doi: 10.1056/NEJMoa0903840

22. Yan H, Parsons DW, Jin G, McLendon R, Rasheed BA, Yuan W, et al. IDH1 and IDH2 mutations in gliomas. N Engl J Med. (2009) 360:76573. doi: 10.1056/NEJMoa0808710

23. Jiang $\mathrm{P}, \mathrm{Du} \mathrm{W}, \mathrm{Wu} \mathrm{M}$. Regulation of the pentose phosphate pathway in cancer. Protein Cell. (2014) 5:592-602. doi: 10.1007/s13238-014-0082-8

24. Weyandt JD, Thompson CB, Giaccia AJ, Rathmell WK. Metabolic alterations in cancer and their potential as therapeutic targets. Am Soc Clin Oncol Educ Book. (2017) 37:825-32. doi: 10.14694/EDBK_175561

25. Medes G, Thomas A, Weinhouse S. Metabolism of neoplastic tissue. IV. A study of lipid synthesis in neoplastic tissue slices in vitro. Cancer Res. (1953) 13:27-9.

26. Reitzer LJ, Wice BM, Kennell D. Evidence that glutamine, not sugar, is the major energy source for cultured HeLa cells. J Biol Chem. (1979) 254:266976.

27. Kroemer G, Galluzzi L, Kepp O, Zitvogel L. Immunogenic cell death in cancer therapy. Annu Rev Immunol. (2013) 31:51-72. doi: 10.1146/annurev-immunol-032712-100008

28. Allard B, Longhi MS, Robson SC, Stagg J. The ectonucleotidases CD39 and CD73: novel checkpoint inhibitor targets. Immunol Rev. (2017) 276:12144. doi: 10.1111/imr.12528

29. Stagg J, Smyth MJ. Extracellular adenosine triphosphate and adenosine in cancer. Oncogene. (2010) 29:5346-58. doi: 10.1038/onc.2010.292

30. Deaglio S, Dwyer KM, Gao W, Friedman D, Usheva A, Erat A, et al. Adenosine generation catalyzed by CD39 and CD73 expressed on regulatory $\mathrm{T}$ cells mediates immune suppression. J Exp Med. (2007) 204:125765. doi: 10.1084/jem.20062512

31. Kong T, Westerman KA, Faigle M, Eltzschig HK, Colgan SP. HIF-dependent induction of adenosine A2B receptor in hypoxia. FASEB J. (2006) 20:224250. doi: 10.1096/fj.06-6419com

32. Tak E, Jung DH, Kim SH, Park GC, Jun DY, Lee J, et al. Protective role of hypoxia-inducible factor-1alpha-dependent CD39 and CD73 in fulminant acute liver failure. Toxicol Appl Pharmacol. (2017) 314:7281. doi: 10.1016/j.taap.2016.11.016

33. Mittal D, Sinha D, Barkauskas D, Young A, Kalimutho M, Stannard K, et al. Adenosine $2 \mathrm{~B}$ receptor expression on cancer cells promotes metastasis. Cancer Res. (2016) 76:4372-82. doi: 10.1158/0008-5472.CAN-16-0544

34. Vander Heiden MG, DeBerardinis RJ. Understanding the intersections between metabolism and cancer biology. Cell. (2017) 168:657-69. doi: 10.1016/j.cell.2016.12.039

35. Doherty JR, Cleveland JL. Targeting lactate metabolism for cancer therapeutics. J Clin Invest. (2013) 123:3685-92. doi: 10.1172/JCI69741

36. Gross MI, Demo SD, Dennison JB, Chen L, Chernov-Rogan T, Goyal $\mathrm{B}$, et al. Antitumor activity of the glutaminase inhibitor CB-839 in triple-negative breast cancer. Mol Cancer Ther. (2014) 13:890901. doi: 10.1158/1535-7163.MCT-13-0870

37. Boysen G, Jamshidi-Parsian A, Davis MA, Siegel ER, Simecka CM, Kore RA, et al. Glutaminase inhibitor CB-839 increases radiation sensitivity of lung tumor cells and human lung tumor xenografts in mice. Int J Radiat Biol. (2019) 95:436-42. doi: 10.1080/09553002.2018.1558299

38. CB-839 + Capecitabine in Solid Tumors and Fluoropyrimidine Resistant PIK3CA Mutant Colorectal Cancer. Available online at: https://ClinicalTrials. gov/show/NCT02861300

39. Study of the Glutaminase Inhibitor CB-839 in Solid Tumors. Available online at: https://ClinicalTrials.gov/show/NCT02071862

40. CANTATA: CB-839 With Cabozantinib vs. Cabozantinib With Placebo in Patients With Metastatic Renal Cell Carcinoma. Available online at: https:// ClinicalTrials.gov/show/NCT03428217

41. Hassanein M, Qian J, Hoeksema MD, Wang J, Jacobovitz M, Ji X, et al. Targeting SLC1a5-mediated glutamine dependence in non-small cell lung cancer. Int J Cancer. (2015) 137:1587-97. doi: 10.1002/ijc.29535

42. Hara Y, Minami Y, Yoshimoto S, Hayashi N, Yamasaki A, Ueda S, et al. Anti-tumor effects of an antagonistic mAb against the ASCT2 amino acid transporter on KRAS-mutated human colorectal cancer cells. Cancer Med. (2019). 9:302-12. doi: 10.1002/cam4.2689 
43. Knott SRV, Wagenblast E, Khan S, Kim SY, Soto M, Wagner M, et al. Erratum: asparagine bioavailability governs metastasis in a model of breast cancer. Nature. (2018) 556:135. doi: 10.1038/nature26162

44. Ho DH, Whitecar JP Jr, Luce JK, Frei E III. L-asparagine requirement and the effect of L-asparaginase on the normal and leukemic human bone marrow. Cancer Res. (1970) 30:466-72.

45. Onuma T, Waligunda J, Holland JF. Amino acid requirements in vitro of human leukemic cells. Cancer Res. (1971) 31:1640-4.

46. Yau T, Cheng PN, Chan P, Chen L, Yuen J, Pang R, et al. Preliminary efficacy, safety, pharmacokinetics, pharmacodynamics and quality of life study of pegylated recombinant human arginase 1 in patients with advanced hepatocellular carcinoma. Invest New Drugs. (2015) 33:496504. doi: 10.1007/s10637-014-0200-8

47. Abou-Alfa GK, Qin S, Ryoo BY, Lu SN, Yen CJ, Feng YH, et al. Phase III randomized study of second line ADI-PEG 20 plus best supportive care versus placebo plus best supportive care in patients with advanced hepatocellular carcinoma. Ann Oncol. (2018) 29:14028. doi: 10.1093/annonc/mdy101

48. Young A, Ngiow SF, Barkauskas DS, Sult E, Hay C, Blake SJ, et al. Co-inhibition of CD73 and A2AR adenosine signaling improves anti-tumor immune responses. Cancer Cell. (2016) 30:391-403. doi: 10.1016/j.ccell.2016.06.025

49. MEDI9447 Alone and in Combination With MEDI4736 in Adult Subjects With Select Advanced Solid Tumors. Available online at: https:// ClinicalTrials.gov/show/NCT02503774

50. Phase 1/1b Study to Evaluate the Safety and Tolerability of CPI-444 Alone and in Combination With Atezolizumab in Advanced Cancers. Available online at: https://ClinicalTrials.gov/show/NCT02655822

51. CPI-006 Alone and in Combination With CPI-444 and With Pembrolizumab for Patients With Advanced Cancers. Available online at: https:// ClinicalTrials.gov/show/NCT03454451

52. FASN Inhibitor TVB-2640, Paclitaxel, and Trastuzumab in Treating Patients With HER2 Positive Advanced Breast Cancer. Available online at: https:// ClinicalTrials.gov/show/NCT03179904

53. TVB-2640 in Combination With Bevacizumab in Patients With First Relapse of High Grade Astrocytoma. Available online at: https:/ClinicalTrials.gov/ show/NCT03032484

54. Svensson RU, Parker SJ, Eichner LJ, Kolar MJ, Wallace M, Brun SN, et al. Inhibition of acetyl-CoA carboxylase suppresses fatty acid synthesis and tumor growth of non-small-cell lung cancer in preclinical models. Nat Med. (2016) 22:1108-19. doi: 10.1038/nm.4181

55. Lally JSV, Ghoshal S, DePeralta DK, Moaven O, Wei L, Masia R, et al. Inhibition of acetyl-CoA carboxylase by phosphorylation or the inhibitor ND-654 suppresses lipogenesis and hepatocellular carcinoma. Cell Metab. (2019) 29:174-82.e5. doi: 10.1016/j.cmet.2018.08.020

56. A Phase I Trial of AZD3965 in Patients With Advanced Cancer. Available online at: https://ClinicalTrials.gov/show/NCT01791595

57. Stein EM, DiNardo CD, Pollyea DA, Fathi AT, Roboz GJ, Altman JK, et al. Enasidenib in mutant IDH2 relapsed or refractory acute myeloid leukemia. Blood. (2017) 130:722-31. doi: 10.1182/blood-2017-04-779405

58. DiNardo CD, Stein EM, de Botton S, Roboz GJ, Altman JK, Mims AS, et al. Durable remissions with ivosidenib in IDH1-mutated relapsed or refractory AML. N Engl J Med. (2018) 378:2386-98. doi: 10.1056/NEJMoa1716984

59. Zachar Z, Marecek J, Maturo C, Gupta S, Stuart SD, Howell K, et al. Nonredox-active lipoate derivates disrupt cancer cell mitochondrial metabolism and are potent anticancer agents in vivo. J Mol Med. (2011) 89:113748. doi: 10.1007/s00109-011-0785-8

60. Alistar A, Morris BB, Desnoyer R, Klepin HD, Hosseinzadeh K, Clark C, et al. Safety and tolerability of the first-in-class agent CPI-613 in combination with modified FOLFIRINOX in patients with metastatic pancreatic cancer: a single-centre, open-label, dose-escalation, phase 1 trial. Lancet Oncol. (2017) 18:770-8. doi: 10.1016/S1470-2045(17)30314-5

61. Jain M, Nilsson R, Sharma S, Madhusudhan N, Kitami T, Souza AL, et al. Metabolite profiling identifies a key role for glycine in rapid cancer cell proliferation. Science. (2012) 336:1040-4. doi: 10.1126/science. 1218595

62. Hosios AM, Hecht VC, Danai LV, Johnson MO, Rathmell JC, Steinhauser $\mathrm{ML}$, et al. Amino acids rather than glucose account for the majority of cell mass in proliferating mammalian cells. Dev Cell. (2016) 36:5409. doi: 10.1016/j.devcel.2016.02.012

63. Muir A, Danai LV, Gui DY, Waingarten CY, Lewis CA, Vander Heiden MG. Environmental cystine drives glutamine anaplerosis and sensitizes cancer cells to glutaminase inhibition. Elife. (2017) 6:e27713. doi: 10.7554/eLife.27713

64. Kekuda R, Prasad PD, Fei YJ, Torres-Zamorano V, Sinha S, Yang-Feng TL, et al. Cloning of the sodium-dependent, broad-scope, neutral amino acid transporter Bo from a human placental choriocarcinoma cell line. J Biol Chem. (1996) 271:18657-61. doi: 10.1074/jbc.271.31.18657

65. Pochini L, Scalise M, Galluccio M, Indiveri C. Membrane transporters for the special amino acid glutamine: structure/function relationships and relevance to human health. Front Chem. (2014) 2:61. doi: 10.3389/fchem.2014.00061

66. Altman BJ, Stine ZE, Dang CV. From krebs to clinic: glutamine metabolism to cancer therapy. Nat Rev Cancer. (2016) 16:61934. doi: 10.1038/nrc.2016.71

67. Jacque N, Ronchetti AM, Larrue C, Meunier G, Birsen R, Willems L, et al. Targeting glutaminolysis has antileukemic activity in acute myeloid leukemia and synergizes with BCL-2 inhibition. Blood. (2015) 126:134656. doi: 10.1182/blood-2015-01-621870

68. Xiang Y, Stine ZE, Xia J, Lu Y, O’Connor RS, Altman BJ, et al. Targeted inhibition of tumor-specific glutaminase diminishes cell-autonomous tumorigenesis. J Clin Invest. (2015) 125:2293-306. doi: 10.1172/JCI75836

69. van Geldermalsen M, Wang Q, Nagarajah R, Marshall AD, Thoeng A, Gao D, et al. ASCT2/SLC1A5 controls glutamine uptake and tumour growth in triple-negative basal-like breast cancer. Oncogene. (2016) 35:32018. doi: 10.1038/onc.2015.381

70. Huang F, Zhao Y, Zhao J, Wu S, Jiang Y, Ma H, et al. Upregulated SLC1A5 promotes cell growth and survival in colorectal cancer. Int J Clin Exp Pathol. (2014) 7:6006-14.

71. Wang Q, Hardie RA, Hoy AJ, van Geldermalsen M, Gao D, Fazli L, et al. Targeting ASCT2-mediated glutamine uptake blocks prostate cancer growth and tumour development. J Pathol. (2015) 236:27889. doi: $10.1002 /$ path. 4518

72. Wang Q, Beaumont KA, Otte NJ, Font J, Bailey CG, van Geldermalsen M, et al. Targeting glutamine transport to suppress melanoma cell growth. Int J Cancer. (2014) 135:1060-71. doi: 10.1002/ijc.28749

73. Pavlova NN, Hui S, Ghergurovich JM, Fan J, Intlekofer AM, White RM, et al. As extracellular glutamine levels decline, asparagine becomes an essential amino acid. Cell Metab. (2018) 27:428-38.e5. doi: 10.1016/j.cmet.2017.12.006

74. Haskell CM, Canellos GP, Leventhal BG, Carbone PP, Block JB, Serpick AA, et al. L-asparaginase: therapeutic and toxic effects in patients with neoplastic disease. N Engl J Med. (1969) 281:102834. doi: 10.1056/NEJM196911062811902

75. Hays JL, Kim G, Walker A, Annunziata CM, Lee JM, Squires J, et al. A phase II clinical trial of polyethylene glycol-conjugated L-asparaginase in patients with advanced ovarian cancer: early closure for safety. Mol Clin Oncol. (2013) 1:565-9. doi: 10.3892/mco.2013.99

76. Patil MD, Bhaumik J, Babykutty S, Banerjee UC, Fukumura D. Arginine dependence of tumor cells: targeting a chink in cancer's armor. Oncogene. (2016) 35:4957-72. doi: 10.1038/onc.2016.37

77. Wheatley DN. Controlling cancer by restricting arginine availabilityarginine-catabolizing enzymes as anticancer agents. Anticancer Drugs. (2004) 15:825-33. doi: 10.1097/00001813-200410000-00002

78. Delage B, Fennell DA, Nicholson L, McNeish I, Lemoine NR, Crook T, et al. Arginine deprivation and argininosuccinate synthetase expression in the treatment of cancer. Int J Cancer. (2010) 126:2762-72. doi: 10.1002/ijc.25202

79. De Santo C, Arscott R, Booth S, Karydis I, Jones M, Asher R, et al. Invariant NKT cells modulate the suppressive activity of IL-10-secreting neutrophils differentiated with serum amyloid A. Nat Immunol. (2010) 11:1039-46. doi: 10.1038/ni.1942

80. Rath M, Muller I, Kropf P, Closs EI, Munder M. Metabolism via arginase or nitric oxide synthase: two competing arginine pathways in macrophages. Front Immunol. (2014) 5:532. doi: 10.3389/fimmu.2014.00532

81. Waickman AT, Alme A, Senaldi L, Zarek PE, Horton M, Powell JD. Enhancement of tumor immunotherapy by deletion of the A2A adenosine receptor. Cancer Immunol Immunother. (2012) 61:917-26. doi: 10.1007/s00262-011-1155-7 
82. Willingham SB, Ho PY, Hotson A, Hill C, Piccione EC, Hsieh J, et al. A2AR antagonism with CPI-444 induces antitumor responses and augments efficacy to anti-PD-(L) 1 and anti-CTLA-4 in preclinical models. Cancer Immunol Res. (2018) 6:1136-49. doi: 10.1158/2326-6066.CIR-18-0056

83. Szutowicz A, Kwiatkowski J, Angielski S. Lipogenetic and glycolytic enzyme activities in carcinoma and nonmalignant diseases of the human breast. $\mathrm{Br} \mathrm{J}$ Cancer. (1979) 39:681-7. doi: 10.1038/bjc.1979.120

84. Menendez JA, Lupu R. Fatty acid synthase and the lipogenic phenotype in cancer pathogenesis. Nat Rev Cancer. (2007) 7:763-77. doi: 10.1038/nrc2222

85. Li JN, Gorospe M, Chrest FJ, Kumaravel TS, Evans MK, Han WF, et al. Pharmacological inhibition of fatty acid synthase activity produces both cytostatic and cytotoxic effects modulated by p53. Cancer Res. (2001) 61:1493-9.

86. Lupu R, Menendez JA. Pharmacological inhibitors of fatty acid synthase (FASN)-catalyzed endogenous fatty acid biogenesis: a new family of anti-cancer agents? Curr Pharm Biotechnol. (2006) 7:483-93. doi: 10.2174/138920106779116928

87. Bandyopadhyay S, Pai SK, Watabe M, Gross SC, Hirota S, Hosobe S, et al. FAS expression inversely correlates with PTEN level in prostate cancer and a PI 3-kinase inhibitor synergizes with FAS siRNA to induce apoptosis. Oncogene. (2005) 24:5389-95. doi: 10.1038/sj.onc. 1208555

88. Roche TE, Hiromasa Y, Turkan A, Gong X, Peng T, Yan X, et al. Essential roles of lipoyl domains in the activated function and control of pyruvate dehydrogenase kinases and phosphatase isoform 1. Eur J Biochem. (2003) 270:1050-6. doi: 10.1046/j.1432-1033.2003.03468.x

89. Stuart SD, Schauble A, Gupta S, Kennedy AD, Keppler BR, Bingham PM, et al. A strategically designed small molecule attacks alpha-ketoglutarate dehydrogenase in tumor cells through a redox process. Cancer Metab. (2014) 2:4. doi: 10.1186/2049-3002-2-4

90. Garcia-Canaveras JC, Chen L, Rabinowitz JD. The tumor metabolic microenvironment: lessons from lactate. Cancer Res. (2019) 79:315562. doi: 10.1158/0008-5472.CAN-18-3726

91. Sonveaux P, Vegran F, Schroeder T, Wergin MC, Verrax J, Rabbani ZN, et al. Targeting lactate-fueled respiration selectively kills hypoxic tumor cells in mice. J Clin Invest. (2008) 118:3930-42. doi: 10.1172/JCI36843

92. Walters DK, Arendt BK, Jelinek DF. CD147 regulates the expression of MCT1 and lactate export in multiple myeloma cells. Cell Cycle. (2013) 12:3175-83. doi: $10.4161 /$ cc.26193

93. Kim Y, Choi JW, Lee JH, Kim YS. Expression of lactate/H $\mathrm{H}^{+}$symporters MCT1 and MCT4 and their chaperone CD147 predicts tumor progression in clear cell renal cell carcinoma: immunohistochemical and the cancer genome atlas data analyses. Hum Pathol. (2015) 46:104-12. doi: 10.1016/j.humpath.2014.09.013

94. Simoes-Sousa S, Granja S, Pinheiro C, Fernandes D, LongattoFilho A, Laus AC, et al. Prognostic significance of monocarboxylate transporter expression in oral cavity tumors. Cell Cycle. (2016) 15:1865-73. doi: 10.1080/15384101.2016.1188239

95. Noble RA, Bell N, Blair H, Sikka A, Thomas H, Phillips N, et al. Inhibition of monocarboxyate transporter 1 by AZD3965 as a novel therapeutic approach for diffuse large B-cell lymphoma and burkitt lymphoma. Haematologica. (2017) 102:1247-57. doi: 10.3324/haematol.2016.163030

96. Berger AH, Brooks AN, Wu X, Shrestha Y, Chouinard C, Piccioni F, et al. High-throughput phenotyping of lung cancer somatic mutations. Cancer Cell. (2016) 30:214-28. doi: 10.1016/j.ccell.2016.06.022

97. Itoh K, Wakabayashi N, Katoh Y, Ishii T, Igarashi K, Engel JD, et al. Keap1 represses nuclear activation of antioxidant responsive elements by Nrf2 through binding to the amino-terminal Neh2 domain. Genes Dev. (1999) 13:76-86. doi: 10.1101/gad.13.1.76

98. Singh A, Misra V, Thimmulappa RK, Lee H, Ames S, Hoque MO, et al. Dysfunctional KEAP1-NRF2 interaction in non-small-cell lung cancer. PLoS Med. (2006) 3:e420. doi: 10.1371/journal.pmed.0030420

99. Romero R, Sayin VI, Davidson SM, Bauer MR, Singh SX, LeBoeuf SE, et al. Keap1 loss promotes Kras-driven lung cancer and results in dependence on glutaminolysis. Nat Med. (2017) 23:1362-8. doi: 10.1038/nm.4407

100. Bustamante E, Pedersen PL. High aerobic glycolysis of rat hepatoma cells in culture: role of mitochondrial hexokinase. Proc Natl Acad Sci USA. (1977) 74:3735-9. doi: 10.1073/pnas.74.9.3735
101. Liu Y, Wu K, Shi L, Xiang F, Tao K, Wang G. Prognostic significance of the metabolic marker hexokinase- 2 in various solid tumors: a meta-analysis. PLoS ONE. (2016) 11:e0166230. doi: 10.1371/journal.pone.0166230

102. Yilmaz M, Christofori G. EMT, the cytoskeleton, and cancer cell invasion. Cancer Metastasis Rev. (2009) 28:15-33. doi: 10.1007/s10555-008-9169-0

103. Nieto MA. Epithelial plasticity: a common theme in embryonic and cancer cells. Science. (2013) 342:1234850. doi: 10.1126/science.1234850

104. Thiery JP, Acloque H, Huang RY, Nieto MA. Epithelialmesenchymal transitions in development and disease. Cell. (2009) 139:871-90. doi: 10.1016/j.cell.2009.11.007

105. Li CF, Chen JY, Ho YH, Hsu WH, Wu LC, Lan HY, et al. Snail-induced claudin-11 prompts collective migration for tumour progression. Nat Cell Biol. (2019) 21:251-62. doi: 10.1038/s41556-018-0268-Z

106. Simeone P, Trerotola M, Franck J, Cardon T, Marchisio M, Fournier I, et al. The multiverse nature of epithelial to mesenchymal transition. Semin Cancer Biol. (2019) 58:1-10. doi: 10.1016/j.semcancer.2018.11.004

107. Puisieux A, Brabletz T, Caramel J. Oncogenic roles of EMT-inducing transcription factors. Nat Cell Biol. (2014) 16:488-94. doi: 10.1038/ncb2976

108. De Craene B, Berx G. Regulatory networks defining EMT during cancer initiation and progression. Nat Rev Cancer. (2013) 13:97110. doi: $10.1038 / \mathrm{nrc} 3447$

109. Hsu DS, Wang HJ, Tai SK, Chou CH, Hsieh CH, Chiu PH, et al. Acetylation of snail modulates the cytokinome of cancer cells to enhance the recruitment of macrophages. Cancer Cell. (2014) 26:534-48. doi: 10.1016/j.ccell.2014.09.002

110. Spoelstra NS, Manning NG, Higashi Y, Darling D, Singh M, Shroyer KR, et al. The transcription factor ZEB1 is aberrantly expressed in aggressive uterine cancers. Cancer Res. (2006) 66:3893-902. doi: 10.1158/0008-5472.CAN-05-2881

111. Pena C, Garcia JM, Garcia V, Silva J, Dominguez G, Rodriguez R, et al. The expression levels of the transcriptional regulators p300 and CtBP modulate the correlations between SNAIL, ZEB1, E-cadherin and vitamin D receptor in human colon carcinomas. Int J Cancer. (2006) 119:2098104. doi: 10.1002/ijc. 22083

112. Postigo AA, Depp JL, Taylor JJ, Kroll KL. Regulation of Smad signaling through a differential recruitment of coactivators and corepressors by ZEB proteins. EMBO J. (2003) 22:2453-62. doi: 10.1093/emboj/cdg226

113. Herranz N, Pasini D, Diaz VM, Franci C, Gutierrez A, Dave N, et al. Polycomb complex 2 is required for E-cadherin repression by the snaill transcription factor. Mol Cell Biol. (2008) 28:477281. doi: 10.1128/MCB.00323-08

114. Yang MH, Hsu DS, Wang HW, Wang HJ, Lan HY, Yang WH, et al. Bmil is essential in Twist1-induced epithelial-mesenchymal transition. Nat Cell Biol. (2010) 12:982-92. doi: 10.1038/ncb2099

115. Lamouille S, Subramanyam D, Blelloch R, Derynck R. Regulation of epithelial-mesenchymal and mesenchymalepithelial transitions by microRNAs. Curr Opin Cell Biol. (2013) 25:200-7. doi: 10.1016/j.ceb.2013.01.008

116. Brabletz S, Brabletz T. The ZEB/miR-200 feedback loop-a motor of cellular plasticity in development and cancer? EMBO Rep. (2010) 11:670 7. doi: 10.1038/embor.2010.117

117. Batlle E, Sancho E, Franci C, Dominguez D, Monfar M, Baulida J, et al. The transcription factor snail is a repressor of E-cadherin gene expression in epithelial tumour cells. Nat Cell Biol. (2000) 2:84-9. doi: 10.1038/35000034

118. Cano A, Perez-Moreno MA, Rodrigo I, Locascio A, Blanco MJ, del Barrio MG, et al. The transcription factor snail controls epithelial-mesenchymal transitions by repressing E-cadherin expression. Nat Cell Biol. (2000) 2:7683. doi: $10.1038 / 35000025$

119. Yang MH, Wu MZ, Chiou SH, Chen PM, Chang SY, Liu CJ, et al. Direct regulation of TWIST by HIF-1alpha promotes metastasis. Nat Cell Biol. (2008) 10:295-305. doi: 10.1038/ncb1691

120. Mani SA, Guo W, Liao MJ, Eaton EN, Ayyanan A, Zhou AY, et al. The epithelial-mesenchymal transition generates cells with properties of stem cells. Cell. (2008) 133:704-15. doi: 10.1016/j.cell.2008.03.027

121. Taube JH, Herschkowitz JI, Komurov K, Zhou AY, Gupta S, Yang J, et al. Core epithelial-to-mesenchymal transition interactome gene-expression signature is associated with claudin-low and metaplastic breast cancer subtypes. Proc Natl Acad Sci USA. (2010) 107:15449-54. doi: 10.1073/pnas.1015095107 
122. Hwang WL, Yang MH, Tsai ML, Lan HY, Su SH, Chang SC, et al. SNAIL regulates interleukin-8 expression, stem cell-like activity, and tumorigenicity of human colorectal carcinoma cells. Gastroenterology. (2011) 141:27991. doi: 10.1053/j.gastro.2011.04.008

123. Hwang WL, Jiang JK, Yang SH, Huang TS, Lan HY, Teng HW, et al. MicroRNA-146a directs the symmetric division of snail-dominant colorectal cancer stem cells. Nat Cell Biol. (2014) 16:268-80. doi: 10.1038/ncb2910

124. Zheng X, Carstens JL, Kim J, Scheible M, Kaye J, Sugimoto H, et al. Epithelial-to-mesenchymal transition is dispensable for metastasis but induces chemoresistance in pancreatic cancer. Nature. (2015) 527:52530. doi: 10.1038/nature16064

125. Prat A, Parker JS, Karginova O, Fan C, Livasy C, Herschkowitz JI, et al. Phenotypic and molecular characterization of the claudinlow intrinsic subtype of breast cancer. Breast Cancer Res. (2010) 12:R68. doi: 10.1186/bcr2635

126. Hsu DS, Lan HY, Huang CH, Tai SK, Chang SY, Tsai TL, et al. Regulation of excision repair cross-complementation group 1 by snail contributes to cisplatin resistance in head and neck cancer. Clin Cancer Res. (2010) 16:4561-71. doi: 10.1158/1078-0432.CCR-10-0593

127. Byers LA, Diao L, Wang J, Saintigny P, Girard L, Peyton M, et al. An epithelial-mesenchymal transition gene signature predicts resistance to EGFR and PI3K inhibitors and identifies Axl as a therapeutic target for overcoming EGFR inhibitor resistance. Clin Cancer Res. (2013) 19:27990. doi: 10.1158/1078-0432.CCR-12-1558

128. Aiello NM, Kang Y. Context-dependent EMT programs in cancer metastasis. J Exp Med. (2019) 216:1016-26. doi: 10.1084/jem.20181827

129. Shen M, Jiang YZ, Wei Y, Ell B, Sheng X, Esposito M, et al. Tinagll suppresses triple-negative breast cancer progression and metastasis by simultaneously inhibiting integrin/FAK and EGFR signaling. Cancer Cell. (2019) 35:6480.e7. doi: 10.1016/j.ccell.2018.11.016

130. Lim SH, Becker TM, Chua W, Ng WL, de Souza P, Spring KJ. Circulating tumour cells and the epithelial mesenchymal transition in colorectal cancer. J Clin Pathol. (2014) 67:848-53. doi: 10.1136/jclinpath-2014-202499

131. Satelli A, Mitra A, Brownlee Z, Xia X, Bellister S, Overman MJ, et al. Epithelial-mesenchymal transitioned circulating tumor cells capture for detecting tumor progression. Clin Cancer Res. (2015) 21:899906. doi: 10.1158/1078-0432.CCR-14-0894

132. Wei T, Zhang X, Zhang Q, Yang J, Chen Q, Wang J, et al. Vimentinpositive circulating tumor cells as a biomarker for diagnosis and treatment monitoring in patients with pancreatic cancer. Cancer Lett. (2019) 452:23743. doi: 10.1016/j.canlet.2019.03.009

133. Yokobori $T$, Iinuma $H$, Shimamura $T$, Imoto $S$, Sugimachi $K$, Ishii $\mathrm{H}$, et al. Plastin3 is a novel marker for circulating tumor cells undergoing the epithelial-mesenchymal transition and is associated with colorectal cancer prognosis. Cancer Res. (2013) 73:2059-69. doi: 10.1158/0008-5472.CAN-12-0326

134. Ueo H, Sugimachi K, Gorges TM, Bartkowiak K, Yokobori T, Muller V, et al. Circulating tumour cell-derived plastin3 is a novel marker for predicting long-term prognosis in patients with breast cancer. $\mathrm{Br} J$ Cancer. (2015) 112:1519-26. doi: 10.1038/bjc.2015.132

135. Kolijn K, Verhoef EI, Smid M, Bottcher R, Jenster GW, Debets R, et al. Epithelial-mesenchymal transition in human prostate cancer demonstrates enhanced immune evasion marked by IDO1 expression. Cancer Res. (2018) 78:4671-9. doi: 10.1158/0008-5472.CAN-17-3752

136. Wang L, Saci A, Szabo PM, Chasalow SD, Castillo-Martin M, DomingoDomenech J, et al. EMT- and stroma-related gene expression and resistance to $\mathrm{PD}-1$ blockade in urothelial cancer. Nat Commun. (2018) 9:3503. doi: 10.1038/s41467-018-05992-x

137. Wu MJ, Chen YS, Kim MR, Chang CC, Gampala S, Zhang Y, et al. Epithelialmesenchymal transition directs stem cell polarity via regulation of mitofusin. Cell Metab. (2019) 29:993-1002.e6. doi: 10.1016/j.cmet.2018.11.004

138. Su YJ, Lai HM, Chang YW, Chen GY, Lee JL. Direct reprogramming of stem cell properties in colon cancer cells by CD44. EMBO J. (2011) 30:318699. doi: 10.1038/emboj.2011.211

139. Yamaguchi H, Takeo Y, Yoshida S, Kouchi Z, Nakamura Y, Fukami K. Lipid rafts and caveolin-1 are required for invadopodia formation and extracellular matrix degradation by human breast cancer cells. Cancer Res. (2009) 69:8594-602. doi: 10.1158/0008-5472.CAN-09-2305
140. Bleazard W, McCaffery JM, King EJ, Bale S, Mozdy A, Tieu Q, et al. The dynamin-related GTPase Dnm1 regulates mitochondrial fission in yeast. Nat Cell Biol. (1999) 1:298-304. doi: 10.1038/13014

141. Chen H, Detmer SA, Ewald AJ, Griffin EE, Fraser SE, Chan DC. Mitofusins Mfn1 and Mfn2 coordinately regulate mitochondrial fusion and are essential for embryonic development. J Cell Biol. (2003) 160:189200. doi: $10.1083 /$ jcb. 200211046

142. Sesaki H, Jensen RE. Division versus fusion: Dnmlp and Fzolp antagonistically regulate mitochondrial shape. J Cell Biol. (1999) 147:699706. doi: $10.1083 /$ jcb.147.4.699

143. Youle RJ, van der Bliek AM. Mitochondrial fission, fusion, and stress. Science. (2012) 337:1062-5. doi: 10.1126/science. 1219855

144. Chen H, Chan DC. Mitochondrial dynamics in mammals. Curr Top Dev Biol. (2004) 59:119-44. doi: 10.1016/S0070-2153(04)59005-1

145. Chen H, Chomyn A, Chan DC. Disruption of fusion results in mitochondrial heterogeneity and dysfunction. J Biol Chem. (2005) 280:26185-92. doi: 10.1074/jbc.M503062200

146. Gomes LC, Di Benedetto G, Scorrano L. During autophagy mitochondria elongate, are spared from degradation and sustain cell viability. Nat Cell Biol. (2011) 13:589-98. doi: 10.1038/ncb2220

147. Mishra P, Chan DC. Metabolic regulation of mitochondrial dynamics. J Cell Biol. (2016) 212:379-87. doi: 10.1083/jcb.201511036

148. Sun Y, Daemen A, Hatzivassiliou G, Arnott D, Wilson C, Zhuang $\mathrm{G}$, et al. Metabolic and transcriptional profiling reveals pyruvate dehydrogenase kinase 4 as a mediator of epithelial-mesenchymal transition and drug resistance in tumor cells. Cancer Metab. (2014) 2:20. doi: 10.1186/2049-3002-2-20

149. Jiang L, Xiao L, Sugiura H, Huang X, Ali A, Kuro-o M, et al. Metabolic reprogramming during TGFbetal-induced epithelial-to-mesenchymal transition. Oncogene. (2015) 34:3908-16. doi: 10.1038/onc.2014.321

150. LeBleu VS, O'Connell JT, Gonzalez Herrera KN, Wikman H, Pantel K, Haigis $\mathrm{MC}$, et al. PGC-1alpha mediates mitochondrial biogenesis and oxidative phosphorylation in cancer cells to promote metastasis. Nat Cell Biol. (2014) 16:992-1003:1-15. doi: 10.1038/ncb3039

151. Dong C, Yuan T, Wu Y, Wang Y, Fan TW, Miriyala S, et al. Loss of FBP1 by snail-mediated repression provides metabolic advantages in basal-like breast cancer. Cancer Cell. (2013) 23:316-31. doi: 10.1016/j.ccr.2013.01.022

152. Kim NH, Cha YH, Lee J, Lee SH, Yang JH, Yun JS, et al. Snail reprograms glucose metabolism by repressing phosphofructokinase PFKP allowing cancer cell survival under metabolic stress. Nat Commun. (2017) 8:14374. doi: $10.1038 /$ ncomms 14374

153. Lee SY, Jeon HM, Ju MK, Kim CH, Yoon G, Han SI, et al. Wnt/Snail signaling regulates cytochrome $\mathrm{C}$ oxidase and glucose metabolism. Cancer Res. (2012) 72:3607-17. doi: 10.1158/0008-5472.CAN-12-0006

154. Murai T. The role of lipid rafts in cancer cell adhesion and migration. Int $J$ Cell Biol. (2012) 2012:763283. doi: 10.1155/2012/763283

155. Zhao W, Prijic S, Urban BC, Tisza MJ, Zuo Y, Li L, et al. Candidate antimetastasis drugs suppress the metastatic capacity of breast cancer cells by reducing membrane fluidity. Cancer Res. (2016) 76:203749. doi: 10.1158/0008-5472.CAN-15-1970

156. Dressler KA, Mathias S, Kolesnick RN. Tumor necrosis factor-alpha activates the sphingomyelin signal transduction pathway in a cell-free system. Science. (1992) 255:1715-8. doi: 10.1126/science.1313189

157. Ogretmen B. Sphingolipid metabolism in cancer signalling and therapy. Nat Rev Cancer. (2018) 18:33-50. doi: 10.1038/nrc.2017.96

158. Kitatani K, Usui T, Sriraman SK, Toyoshima M, Ishibashi M, Shigeta S, et al. Ceramide limits phosphatidylinositol-3-kinase C2 $\beta$-controlled cell motility in ovarian cancer: potential of ceramide as a metastasis-suppressor lipid. Oncogene. (2016) 35:2801-12. doi: 10.1038/onc.2015.330

159. Luo X, Cheng C, Tan Z, Li N, Tang M, Yang L, et al. Emerging roles of lipid metabolism in cancer metastasis. Mol Cancer. (2017) 16:76. doi: 10.1186/s12943-017-0646-3

160. Lucenay KS, Doostan I, Karakas C, Bui T, Ding Z, Mills GB, et al. Cyclin E associates with the lipogenic enzyme ATP-citrate lyase to enable malignant growth of breast cancer cells. Cancer Res. (2016) 76:240618. doi: 10.1158/0008-5472.CAN-15-1646

161. Frisch SM, Ruoslahti E. Integrins and anoikis. Curr Opin Cell Biol. (1997) 9:701-6. doi: 10.1016/S0955-0674(97)80124-X 
162. Schafer ZT, Grassian AR, Song L, Jiang Z, Gerhart-Hines Z, Irie HY, et al. Antioxidant and oncogene rescue of metabolic defects caused by loss of matrix attachment. Nature. (2009) 461:109-13. doi: 10.1038/nature08268

163. Berezovskaya O, Schimmer AD, Glinskii AB, Pinilla C, Hoffman RM, Reed JC, et al. Increased expression of apoptosis inhibitor protein XIAP contributes to anoikis resistance of circulating human prostate cancer metastasis precursor cells. Cancer Res. (2005) 65:2378-86. doi: 10.1158/0008-5472.CAN-04-2649

164. Howard EW, Leung SC, Yuen HF, Chua CW, Lee DT, Chan KW, et al. Decreased adhesiveness, resistance to anoikis and suppression of GRP94 are integral to the survival of circulating tumor cells in prostate cancer. Clin Exp Metastasis. (2008) 25:497-508. doi: 10.1007/s10585-008-9157-3

165. DeNicola GM, Karreth FA, Humpton TJ, Gopinathan A, Wei C, Frese K, et al. Oncogene-induced Nrf2 transcription promotes ROS detoxification and tumorigenesis. Nature. (2011) 475:106-9. doi: 10.1038/nature10189

166. Jiang L, Shestov AA, Swain P, Yang C, Parker SJ, Wang QA, et al. Reductive carboxylation supports redox homeostasis during anchorage-independent growth. Nature. (2016) 532:255-8. doi: 10.1038/nature17393

167. Piskounova E, Agathocleous M, Murphy MM, Hu Z, Huddlestun SE, Zhao Z, et al. Oxidative stress inhibits distant metastasis by human melanoma cells. Nature. (2015) 527:186-91. doi: 10.1038/nature15726

168. Shaul YD, Freinkman E, Comb WC, Cantor JR, Tam WL, Thiru P, et al. Dihydropyrimidine accumulation is required for the epithelial-mesenchymal transition. Cell. (2014) 158:1094-109. doi: 10.1016/j.cell.2014.07.032

169. Ulanet DB, Couto K, Jha A, Choe S, Wang A, Woo HK, et al. Mesenchymal phenotype predisposes lung cancer cells to impaired proliferation and redox stress in response to glutaminase inhibition. PLoS ONE. (2014) 9:e115144. doi: 10.1371/journal.pone.0115144

170. Kuo TC, Chen CK, Hua KT, Yu P, Lee WJ, Chen MW, et al. Glutaminase 2 stabilizes dicer to repress snail and metastasis in hepatocellular carcinoma cells. Cancer Lett. (2016) 383:282-94. doi: 10.1016/j.canlet.2016.10.012

171. Yang L, Zhang F, Wang X, Tsai Y, Chuang KH, Keng PC, et al. A FASN-TGFbeta1-FASN regulatory loop contributes to high EMT/metastatic potential of cisplatin-resistant non-small cell lung cancer. Oncotarget. (2016) 7:5554354. doi: 10.18632/oncotarget.10837

172. Lim JCW, Kwan YP, Tan MS, Teo MHY, Chiba S, Wahli W, et al. The role of PPARbeta/delta in melanoma metastasis. Int J Mol Sci. (2018) 19:2860. doi: 10.3390/ijms19102860

173. Lin SJ, Yang DR, Wang N, Jiang M, Miyamoto H, Li G, et al. TR4 nuclear receptor enhances prostate cancer initiation via altering the stem cell population and EMT signals in the PPARG-deleted prostate cells. Oncoscience. (2015) 2:142-50. doi: 10.18632/oncoscience.121

174. Yu H, Duan P, Zhu H, Rao D. miR-613 inhibits bladder cancer proliferation and migration through targeting SphK1. Am J Transl Res. (2017) 9:1213-21.

175. Fan Z, Jiang H, Wang Z, Qu J. Atorvastatin partially inhibits the epithelial-mesenchymal transition in A549 cells induced by TGF-betal by attenuating the upregulation of SphK1. Oncol Rep. (2016) 36:101622. doi: 10.3892/or.2016.4897

176. Liu H, Ma Y, He HW, Zhao WL, Shao RG. SPHK1 (sphingosine kinase 1) induces epithelial-mesenchymal transition by promoting the autophagy-linked lysosomal degradation of $\mathrm{CDH} 1 / \mathrm{E}$-cadherin in hepatoma cells. Autophagy. (2017) 13:900-13. doi: 10.1080/15548627.2017. 1291479

177. Xu CY, Liu SQ, Qin MB, Zhuge CF, Qin L, Qin N, et al. SphK1 modulates cell migration and EMT-related marker expression by regulating the expression of p-FAK in colorectal cancer cells. Int J Mol Med. (2017) 39:127784. doi: 10.3892/ijmm.2017.2921

178. Zeng Y, Yao X, Chen L, Yan Z, Liu J, Zhang Y, et al. Sphingosine1-phosphate induced epithelial-mesenchymal transition of hepatocellular carcinoma via an MMP-7/ syndecan-1/TGF-beta autocrine loop. Oncotarget. (2016) 7:63324-37. doi: 10.18632/oncotarget.11450

179. Na DC, Lee JE, Yoo JE, Oh BK, Choi GH, Park YN. Invasion and EMTassociated genes are up-regulated in B viral hepatocellular carcinoma with high expression of CD133-human and cell culture study. Exp Mol Pathol. (2011) 90:66-73. doi: 10.1016/j.yexmp.2010.10.003

180. Ito H, Duxbury M, Zinner MJ, Ashley SW, Whang EE. Glucose transporter1 gene expression is associated with pancreatic cancer invasiveness and MMP-2 activity. Surgery. (2004) 136:548-56. doi: 10.1016/j.surg.2004.05.032

Conflict of Interest: The authors declare that the research was conducted in the absence of any commercial or financial relationships that could be construed as a potential conflict of interest.

Copyright (c) 2020 Sun and Yang. This is an open-access article distributed under the terms of the Creative Commons Attribution License (CC BY). The use, distribution or reproduction in other forums is permitted, provided the original author(s) and the copyright owner(s) are credited and that the original publication in this journal is cited, in accordance with accepted academic practice. No use, distribution or reproduction is permitted which does not comply with these terms. 